\title{
New Symposium Tutorial Program Debuts at the 1995 MRS Fall Meeting
}

The Materials Research Society will present a new program of Symposium Tutorials at the 1995 Fall Meeting in Boston. Unlike past meetings where Short Courses and Tutorials were offered as a program separate from the symposia, the Symposium Tutorials are each coordinated directly with a particular symposium. A major benefit for meeting attendees is that they pay only a nominal fee to cover the cost of reproducing the instructors' notes (about \$25).

The Symposium Tutorials scheduled for the Fall Meeting include:

- Symp. G: Epitaxial Metal Oxide Thin Films and Heterostructures

- Symp. H: Silicides For Integrated Circuits: Materials Aspects and Technological Implementation

- Symp. J: In Situ Electron Microscopy: Methodology and Range of Applications
- Symp. K: Effects of Strain on the Electronic and Vibrational Properties of Semiconductors and Semiconductor Microstructures

- Symp. Q: Introduction to Fracture: The Brittle/Ductile Transition and Dynamical Instabilities in Crack Propagation

- Symp. W: Electrical, Optical and Magnetic Properties of Organic Solids

- Symp. X: Federal Materials Research Programs and Opportunities

- Symp CC: Novel Materials Research Opportunities at National Synchrotron and Free Electron Laser Facilities

- Symp DD: Electron Emission From Diamond

The topics and instructors were chosen by the respective symposium organizers and meeting chairs. The topics should address areas of growing interest to the participants of the respective symposia.
Topics of more general interest may be approved by the meeting chairs and they will be listed with Symposium X. Most of the Symposium Tutorials are scheduled just prior to the symposium program, but in some instances, the tutorials are integrated directly into the schedule of the symposium. The Symposium Tutorials will be presented in the same rooms as the respective symposia. All tutorials are planned for a half day. Copies of the instructors' notes will be available at the meeting for preregistered attendees.

The change from the previous Short Course Program format came about as a result of recommendations from a task force headed by Robert Hull. The general outcome of that task force was that the Tutorials should be directed specifically to the meeting attendees and that they should be as current and relevant as the meeting symposia. To achieve these goals the major input for the selection of tutorials was now transferred to the Symposia

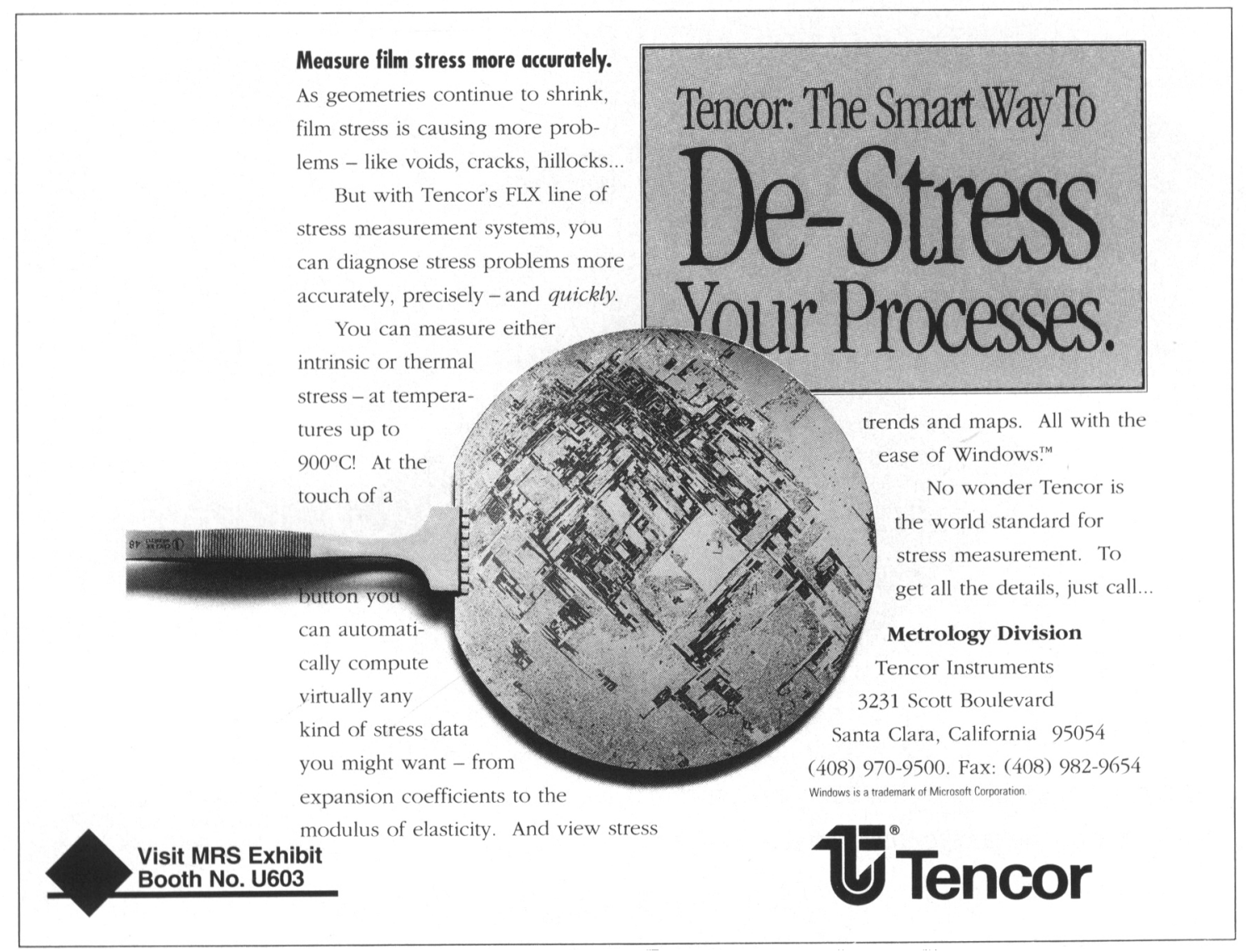

Circle No. 51 on Reader Service Card. 
Organizers and the Meeting Chairs. The Continuing Education Subcommittee will assist in the organization, and it will become part of the Program Committee.

The Symposium Tutorials are expected to be helpful in not only providing tutorial and background information, but also in providing focus to the major issues of the respective symposia. The Subcommittee appreciates the value of in-depth and extended discussions by recognized experts and involved participants, and is hopeful that this new format and low cost will prove particularly attractive to all of the meeting attendees.

ROBERT J. NEMANICH Chair, Continuing Education Subcommittee

MIR

\section{See MRS Homepage on World Wide Web http://www.mrs.org/}

\section{NEW ENTREPRENEUR PROGRAM... to be held at the 1995 MRS Fall Meeting!}

The 1995 MRS Fall Exhibit will feature an Entrepreneur Program to be held on the third floor of the Westin Hotel/Copley Place.

\section{WESTIN HOTEL SHOW HOURS:}

Tuesday, 9:30 a.m. - 5:00 p.m.

Wednesday, 9:30 a.m. - 12:30 p.m. and 7:30 p.m. $-10: 00$ p.m.

Thursday, 9:30 a.m. - 12:30 p.m.

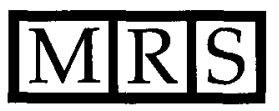

For a free exhibit admission pass contact Mary E. Kaufold, MRS Advertising and Exhibits Manager, at (412) 367-3036; fax (412) 367-4373; email kaufold@ mrs.org
UNMATCHED PRECISION. QUALITY SEMICONDUCTOR MATERIALS PROCESSING SINCE 1967.

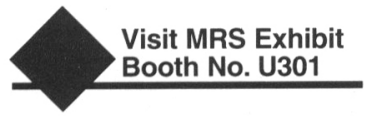

SEMICONDUCTOR PROCESSING COMPANY

409 East First St., Boston, MA 02127 617/269-4422 FAX: 617/269-4659 (1)

\section{.

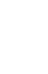

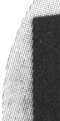

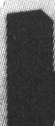
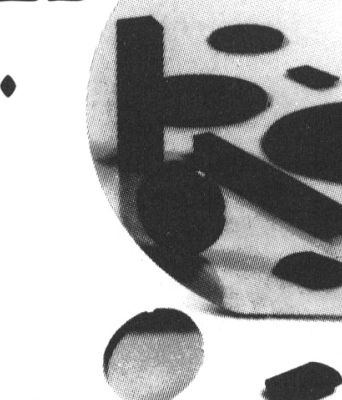

. (5) (5)

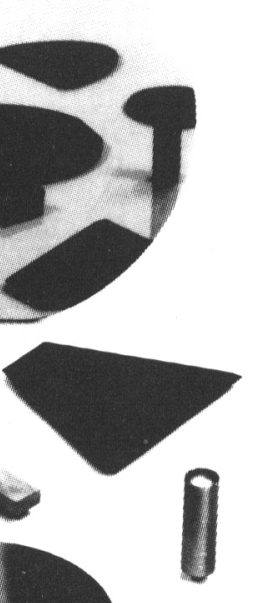
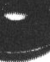

\section{ADVANCED TECHNOLOGY.}

Simultaneous two-sided polishing for high precision micromachining applications. $25 \mathrm{~mm}$ through $125 \mathrm{~mm}$ silicon wafers with <2um thickness variation!

SPECIAL MATERIALS. Silicon, germanium and a variety of III-V compound semiconductors.

CUSTOM SERVICES. Complete wafer fabrication. Slicing, grinding, lapping, polishing and dicing.

FLEXIBILITY. Virtually any orientation, shape, size or thickness. Research or production quantities in 4 weeks or less.

QUALITY CONTROL. Quality and calibration systems conform to MIL-I-45208A and MIL-I-45662. 